\title{
The Impact of Data Communications Messages in the Terminal Area on Flight Crew Workload and Eye Scanning
}

\author{
James R. Comstock, Jr., Brian T. Baxley \\ NASA Langley Research Center, Hampton, VA \\ Robert M. Norman, Ph.D. \\ The Boeing Company Research and Technology, Hampton, VA \\ Kyle K. E. Ellis \\ University of Iowa and NASA Graduate Student Researchers Program \\ Cathy A. Adams, Kara A. Latorella, William A. Lynn \\ NASA Langley Research Center, Hampton, VA
}

\begin{abstract}
This paper, to accompany a discussion panel, describes a collaborative FAA and NASA research study to determine the effect Data Communications (Data Comm) messages have on flight crew workload and eye scanning behavior in busy terminal area operations. In the Next Generation Air Transportation System Concept of Operations, for the period 2017-2022, the FAA envisions Data Comm between controllers and the flight crew to become the primary means of communicating non-time critical information. Four research conditions were defined that span current day to future equipage levels (Voice with Paper map, Data Comm with Paper map, Data Comm with Moving Map Display with ownship position displayed, Data Comm with Moving Map, ownship and taxi route displayed), and were used to create arrival and departure scenarios at Boston Logan Airport. Preliminary results for workload, situation awareness, and pilot head-up time are presented here. Questionnaire data indicated that pilot acceptability, workload, and situation awareness ratings were favorable for all of the conditions tested. Pilots did indicate that there were times during final approach and landing when they would prefer not to hear the message chime, and would not be able to make a quick response due to high priority tasks in the cockpit.
\end{abstract}

\section{INTRODUCTION}

The Next Generation Air Transportation System Concept of Operations supports employment of an electronic Data Communications system, to enable communication of non-time critical information and events between flight deck and ground facilities. Transferred information could include expected taxi and flight clearances, weather, and real-time trajectory control. Deploying such a system is intended to sustain expected increases in air traffic by 2025 (Joint Planning and Development Office $\{$ JPDO $\}, 2007)$ and to assist Air Navigation Service Providers (ANSPs) in managing air traffic more efficiently (JPDO, 2007). For flight crews, Data Comm serves as a means to share weather, airport surface operations, and Trajectory-Based Operations (TBO) information. Additionally, Data Comm and related automation on the flight deck allows real-time data to be transmitted, thereby improving decision making for controllers and pilots (JPDO, 2007).

The FAA plans on implementing this Data Communications (Data Comm) System in three segments. Segment One will occur from the years 2012 - 2016, and will be characterized by current equipage and the use of voice communications as the primary mode. Segment Two will occur in the years 2017 - 2022, and will be characterized by the gradual transition from voice to Data Comm (both in terms of procedures and equipage) during the segment time period. Segment Three will occur the year 2023 and subsequent, and is characterized by Data Comm being the primary mode of communication.

An interagency agreement was established between the FAA and NASA to conduct a Human-inthe-Loop simulation to study Data Comm functionality from the flight crew perspective and how it will contribute to the ultimate NextGen goal of increased efficiency and capacity. This paper describes the research and selected results from the study which employed 22 current, commercial airline pilots. To identify Data Comm operational capabilities, limitations, and system requirements, the experiment used a high-fidelity flight simulator at NASA Langley, a complex and operationally realistic simulation of arrivals and departures from Boston Logan Airport, 
and created high flight-crew workload by requiring the simulator to be hand-flown in a heavy traffic density scenario.

As background for the research study, an extensive literature review was conducted. Due to space limitations, that information will not be presented here. The interested reader is referred to Norman \& Baxley (2010), and Shelton, Prinzel, Arthur, Jones, Allamandola, and Bailey (2009) for additional information and references.

\section{EXPERIMENT DESIGN OVERVIEW}

The FAA/NASA Interagency Agreement for this experiment specified the focus of research to be Data Comm uplink messages (ATC to flight crew), especially expected taxi route information. A question of interest was whether controllers should be inhibited from sending taxi or expected taxi messages during periods of potential high flight-crew workload in a busy terminal area.

\section{Research Questions}

To determine if data-linked messages are acceptable to flight crews in a high workload environment such as arrivals and departures at Boston Logan International Airport, the research team defined three key research questions:

- Will pilot Workload and Situational Awareness be affected as a function of the use of Data Comm in the Terminal environment as compared to the Voice Baseline?

- Will pilot Workload and Situational Awareness be affected by display attributes in conjunction with Data Comm (no airport map display, ownship position on Moving Map Display (MMD), and ownship plus Route on the MMD)?

- Will pilots find Data Comm within this experiment operationally acceptable?

This meant that there were four communications and display conditions:

a) Voice Communications with Paper map

b) Data Communications with Paper map

c) Data Communications with Moving map display with ownship position displayed

d) Data Communications with Moving map display with ownship and Taxi Route displayed

The moving map and taxi route displays were of interest to researchers as a means of maintaining or enhancing situation awareness when other infor- mation present in voice-only environments (e.g., voice party line information) was reduced.

\section{Scenarios and Environment}

Data was collected from eleven crews (22 subject pilots) in the Integration Flight Deck (IFD) at NASA Langley. This simulator is a full-mission high fidelity simulator representative of a modern commercial transport aircraft. The Main Instrument Panel contains Primary Flight Displays (PFD) and Navigation Displays (ND), the EICAS, flight instruments (airspeed, altitude, attitude, etc), as well as standby altimeter and gear lever. The Center Control Stand consists of a typical twin-engine throttle quadrant, flap and speed brake controls, reverse thrust, spoiler handles, dual Flight Management System (FMS) Control Display Units (CDUs), and several electronic panels for controlling the PFD and ND, as well as researcher specified systems. The IFD houses a standard Mode Control Panel under the glare shield, and a complete Overhead Panel.

The IFD visual system is a panorama system using five video projectors that provide $200^{\circ}$ horizontal by $40^{\circ}$ vertical field-of-view, with $1440 \mathrm{x}$ 1024 resolution. A Rockwell Collins EP-1000 Boston Logan (BOS) database was used for the out-thewindow projection of the airport surface, taxiways, runways, buildings, obstructions, signs, and airport terrain and cultural features in a day, VMC setting.

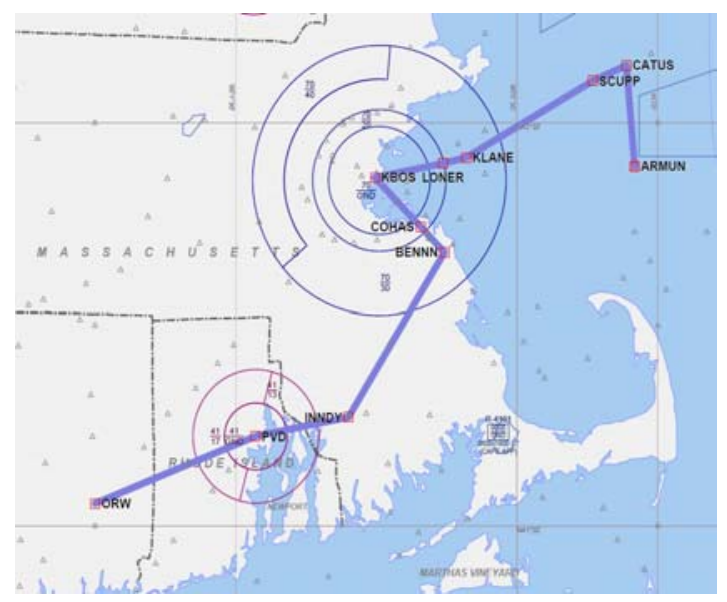

Figure 1. Arrival Procedures and Airspace

For this study, arrivals and departures to Runways 27 and 33L (See Figure 1) were chosen, with airborne routes that provided realistic profiles and workload from 18,000 feet to landing, and taxi routes 
that to the maximum extent practicable matched those used in prior research at the FAA Tech Center.

Traffic levels consisted of approximately 20 other aircraft during each of the 15 to 20 minute scenarios (approximating 70 aircraft per hour at Boston), and included accurate out-the-window and audio emulation of that traffic. During the departure scenarios when the subject flight crew waited to begin their taxi operations, they would see other aircraft clearing the runway and hear two-way communication between the aircraft and Air Traffic Control (ATC). To maximize realism and taskloading, ATC would also issue the subject flight crew voice instructions that required them to interact with the out-the-window traffic. For example, "NASA 557, Runway 27, taxi via your datalink route. Remain behind the CRJ-200 at your 12:00 o'clock turning on Bravo. Hold Short Runway 33 Left.”

Real-world procedures and operations were simulated or emulated to the maximum extent possible, including the use of checklists (Approach, Before Landing, After Landing, Taxi, etc). Each crew completed eight arrival scenarios into Boston Logan International Airport, including taxiing to a gate, and eight departure scenarios that had the crew taxi from the gate to the departure end of the runway. The eight arrivals and eight departures represented two replicates of four arrivals and four departure scenarios.
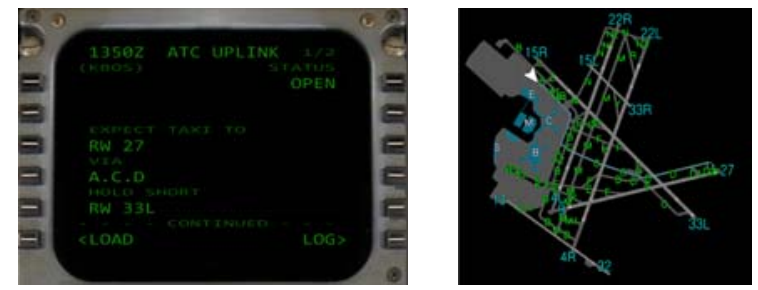

Figure 2. Expected Taxi Message and Map Display

Datalink messages were received and sent via the Control Display Unit (CDU), and the CDU also provided the ability to load them into the Moving Map Display as graphical routes. Figure 2 shows examples of the CDU and Map displays.

A ten-camera eye-tracking system (SmartEye ${ }^{\mathrm{TM}}$ with SmartEye Pro 5.5 software) was used to record eye and head tracking data for both subject pilots during the runs (five cameras for each crew member). The system used in this experiment did not require any attachments to the test subjects.

\section{Data Comm Messages and Graphical Display}

Data Comm messages were formatted in accordance with RTCA DO-305, DO-219, and DO269, and based on a Boeing 747 FANS 1/A implementation. This experiment focused primarily on two specific CPDLC uplink messages (ATC to flight crew):

- taxi clearances (both from terminal to departure runway, and from landing roll-out to the terminal area)

- expected taxi clearances (operationally given by ATC for flight crew planning purposes, expected to be 15 minutes prior to pushback from the terminal area, or prior to Top Of Descent for arriving aircraft)

To retain the realism of the scenarios and preclude the subject pilots from always expecting these messages, other Data Comm uplink messages were included in the scenarios, such as changes to altimeter settings, notification of a new Automatic Terminal Information Service (ATIS) recording, and issuing a frequency change to the next controller (e.g., from Approach Control to Tower controller). In addition to responding to all uplink messages appropriately (ROGER, WILCO, UNABLE, or STANDBY), the subject pilots were required to use Data Comm downlink messages such as requesting pushback, requesting engine start, and requesting their taxi clearance.

When the Data Comm message was received, a chime sounded in the cockpit and the Pilot Monitoring (PM, always the First Officer in this experiment) depressed the ATC button on the CDU to read the message. On page one of the display, the PM loads the text clearance onto the Moving Map Display as a graphical route (if the scenario is the one condition that includes displaying the taxi route graphically). The "Expected Taxi” message is displayed as a dotted cyan line from the terminal gate to the departure runway, with no red hold short lines for any runway (a decision made to reinforce visually that an "Expected Taxi" message is not a taxi clearance, and is for planning purposes only). The same procedure applies for an arrival scenario where ATC sends an uplink message of the taxi route from runway to terminal for planning purposes, the PM loads the route onto the MMD (if appropriate for that condition), then sends a downlink of "ROGER" to acknowledge the "Expected Taxi" clearance. ROGER automatically replaces WILCO on the display for informational type messages (such as expected taxi clearances, changes to the ATIS or altimeter settings, etc.). 
The actual "Taxi" clearance is accessed in a similar fashion by the PM. A chime sounds when the uplink is received, the PM reads the message and loads the graphical representation on the MMD (if appropriate) from page one. The taxi clearance is shown as a dotted white line from ownship position to the first active runway, where it ends in a solid red bar representing the Hold Short line. The rest of the route past the red Hold Short bar remains dotted cyan. When the PM acknowledges the taxi clearance with a WILCO on Page 2 of the CDU message display, the dotted white line turns to a solid magenta.

In the voice condition used to simulate operational procedures in effect today, the subject flight crews were cleared to begin taxiing the aircraft once they acknowledged and read back the ATC taxi clearance. However the Data Comm environment is slightly different. A Data Comm taxi clearance was just the route, and not permission to begin taxiing the aircraft. The flight crew in Data Comm scenarios received the route via Data Comm, but then required a voice instruction from the ground controller to begin taxiing the aircraft. The voice message exchange might be: "Ground, NASA557 ready to taxi”, “NASA557, Ground, taxi via data link route”, "NASA557, Roger."

\section{RESULTS}

The results presented here are a subset of the overall results of the study, due to space limitations, and will focus on an overview of subjective workload, situation awareness, and eye-tracker indices of pilot head-up and head down time. A NASA publication (in press) will contain comprehensive and detailed results.

Crew Workload. Subjects used the Bedford workload rating scale to rate the workload associated with surface/taxi operations immediately after both arrival and departure scenarios.

Figure 3 presents the results from the post scenario questionnaire for workload during surface operations, across the experimental conditions, and by seat in the cockpit. On the figure X-axis, a 1 (left) indicates "workload insignificant", a 5 is "reduced spare capacity", and a 10 (right) indicates "task abandoned". As can be seen from the figures the majority of responses were indicative of low workload (ratings of 1 to 3). Pilot Flying (PF) and Pilot Monitoring (PM or F.O.) ratings did not differ significantly for surface/taxi operations $\left(X^{2}(1)=\right.$ 2.339, $\mathrm{p}=0.126)$.

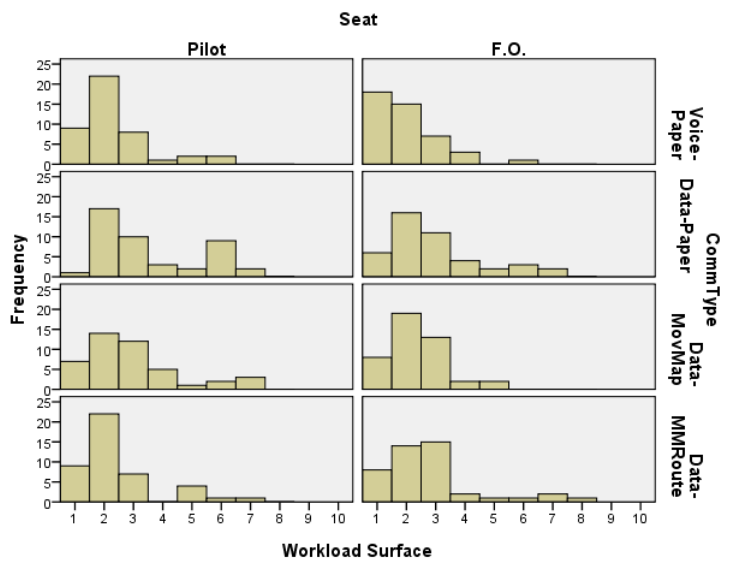

Figure 3. Post Scenario workload ratings for surface operations.

Situation Awareness. A series of Situation Awareness questions were also administered as part of the Post Scenario Questionnaire. Figure 4 presents responses from a question assessing a crew member's overall understanding of the situation during surface operations. Here the responses reflect a high degree of understanding of the situation across all of the experimental conditions.

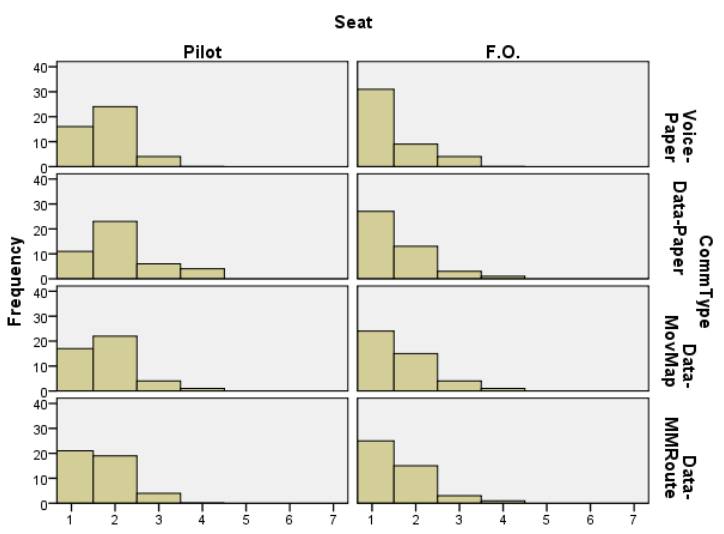

Figure 4. Post Scenario rating of understanding of the situation for surface ops $(1=$ High, $7=$ Low $)$.

Head-up / Head down time. Since the pilot was hand flying on approaches and was on the side of the cockpit with the nose-wheel tiller for taxi, higher percentages (relative to the PM) of head-up time were expected and were found in the data as shown in Figure 5. For the PF there was a slight decrease in head-up time for the Data Comm conditions. 


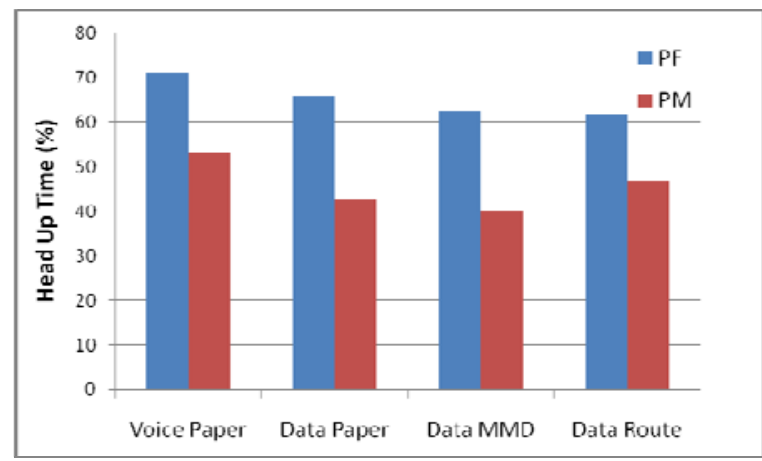

Figure 5. Crew head up time during departure taxi operations.

Since the PM was generally handling the Data Comm messages and the related CDU interface, each of the "Data" conditions reflected a lower percentage of head-up time relative to the baseline Voice Paper condition, but only on the order of $12 \%$ or less as shown in the figure. This increase in head-down time was not deemed unacceptable by the crews, nor was it reflected in workload or Situation Awareness preference ratings.

Display Preference for Situation Awareness. In the post-experiment questionnaire there were a series of questions directed at display preferences. Figure 6 presents the results of a question addressing display preferences for the highest situation awareness.

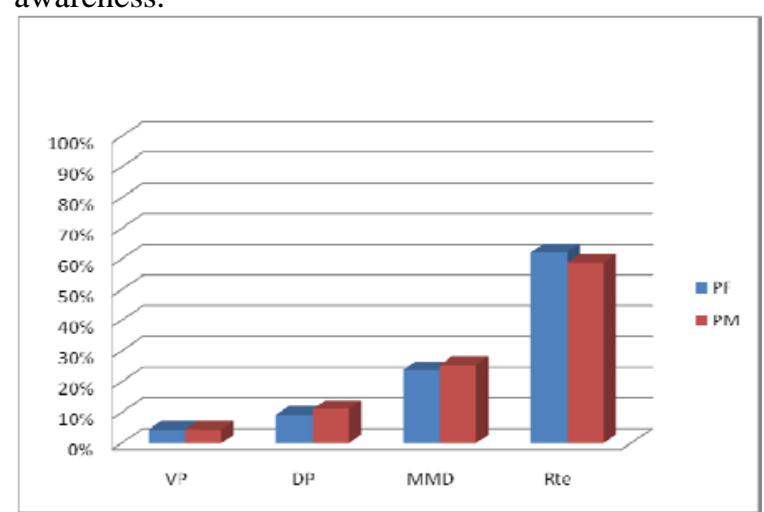

Figure 6. Display preference by crew position for highest situation awareness.

These data illustrate a preference for having a map with ownship position, and especially route information on that map (significant differences were noted between all conditions).

\section{CONCLUSIONS}

- Post scenario acceptability ratings were high for all Data Comm scenarios. Post experiment questionnaire results indicated high acceptance of Data Comm in the terminal area, however voice should be used for time critical or safety related communication.

- Post scenario workload and situation awareness ratings were favorable for all the Data Comm conditions evaluated.

- Post experiment display comparison preference ratings for Situation Awareness showed higher ratings when a Moving Map Display was available, and still higher ratings for the condition with loadable routes on the Moving Map Display.

- All crews indicated in the questionnaires and verbal debrief that Data Comm during approaches above 10,000' would be acceptable. Some crews (45\%) said that Data Comm messages from 10,000' to the Final Approach Fix should not be allowed, or should be restricted to those that are of critical importance.

- All crews indicated that Data Comm should not be used after the Final Approach Fix until below 80 Knots Indicated Air Speed during landing roll-out. However many crews also stated Data Comm messages during that time would be acceptable if they were not accompanied by a chime and the flight crew was not expected to immediately respond to the message.

\section{REFERENCES}

Joint Planning \& Development Office (2007). Concept of Operations for the Next Generation Air Transportation System, (Version 2.0, August, 2007)

Norman, R. M., and Baxley, B. T. (2010). Pilot Workload and Acceptability using Data Comm CPDLC Messages in the Terminal Area. AIAA (in press)

Shelton, K. J., Prinzel, L. J., III, Arthur, J. J., III, Jones, D. R., Allamandola, A. S., and Bailey, R. E. (2009). Data-Link and Surface Map Traffic Intent Displays for NextGen 4DT and Equivalent Visual Surface Operations. SPIE Defense, Security, and Sensing 2009, 13-17 Apr. 2009, Orlando, FL, United States. 